\title{
Floral trait variation in Spergularia marina (Caryophyllaceae): ontogenetic, maternal family, and population effects
}

\author{
SUSAN J. MAZER* $†$ \& VERONIQUE A. DELESALLE $\ddagger$ \\ $\uparrow$ Department of Biological Sciences, University of California, Santa Barbara, CA 93106 and $\ddagger$ Department of Biology, \\ Gettysburg College, Gettysburg, PA 17325, U.S.A.
}

\begin{abstract}
Traits expressed by modular organisms present difficulties when estimating the genetic component to their variation if their phenotype changes as an individual ages, confounding ontogenetic and genetic sources of phenotypic variation. For such traits, it is necessary to control for ontogenetic effects in order to estimate accurately the degree of genetic variation in a trait. To measure the magnitude of ontogenetic change in floral traits and to determine whether it may obscure underlying genetic sources of floral trait variation in the autogamous annual, Spergularia marina (Caryophyllaceae), we monitored the expression of floral traits over a five-week period in greenhouse-raised plants from four California wild populations. From 130 individuals representing 8-10 maternal families per population, we sampled one flower per week to record the number of ovules, normal anthers (the number of which is positively correlated with pollen production per flower), abnormal anthers (those that grade phenotypically into petals), and petals; and the areas of a single petal and the entire corolla. All traits except the number of abnormal anthers exhibited strong temporal changes in phenotype, although the direction and magnitude of the change differed among traits. To determine whether populations appear to be evolving independently, we examined differences among them in floral trait means, in the magnitude of among-family variation, and in the degree to which they show temporal change in floral trait means. There were significant differences among population means for all traits except the number of ovules and petals per flower. In addition, populations differ in those traits that exhibit significant differences among maternal family means. For most traits, populations also differ in the magnitude of week-to-week changes in mean phenotype, suggesting the presence of genetic variation among populations in the expression of temporal change in floral traits. Finally, for most traits, the magnitude and significance of differences among populations and among maternal family means changed over time. Consequently, broad-sense heritability estimates, predictions of the response to selection, and measures of interpopulation divergence for floral traits are sensitive to the time of flower sampling in $S$. marina. The role of natural selection in moulding ontogenetic variation in floral traits has not been extensively studied in any species, but the presence of genetic variation among populations observed here suggests that this character is open to evolutionary change.
\end{abstract}

Keywords: autogamy, canalization, Caryophyllaceae, maternal effects, sex allocation, Spergularia.

\section{Introduction}

The relative amounts of ontogenetic, genetic and environmental sources of variation in floral traits in wild plant populations determine the short-term potential for natural selection to cause evolutionary change. To estimate the potential role of selection in

*Correspondence.

(C) 1996 The Genetical Society of Great Britain. moulding floral traits in natural populations, many investigators have measured the magnitudes of genetic or environmental (natural or imposed) sources of variation (Braak \& Kho, 1958; Schoen, 1982; Thompson, 1987; Thomson et al., 1989; Young \& Stanton, 1990; Mazer \& Schick, 1991a,b; Zimmerman, 1991; Carr \& Fenster, 1994). Others have focussed on developmental sources of variation and have examined the effects of plant age or flowering 
sequence on characters such as flower size, gender expression, or gamete production (Bawa \& Webb, 1983; Holtsford, 1985; Solomon, 1985; Thomson, 1985, 1989; Pellmyr, 1987; Lee, 1988; Nybom, 1989; Thompson \& Pellmyr, 1989; Kang \& Primack, 1991; Thomson \& Barrett, 1991; Ashman \& Baker, 1992; Emms, 1993). Very few studies, however, provide measures of both ontogenetic and genetic sources of variation in floral traits (Young \& Stanton, 1990; Armbruster, 1991; Diggle, 1993).

Studies of ontogenetic change (and, in genetic terms, the repeatability) of traits expressed by modular organs can identify those traits for which ontogenetic and genetic sources of variation can be easily confounded when sampling individuals, maternal families or populations. Such studies may also detect genotype $\times$ age interactions, which indicate the presence of genetic variation in the degree of ontogenetic change in floral traits and provide evidence that natural selection can act on the expression of ontogenetic change itself (if it influences individual expected fitness; cf. Bradshaw, 1965).

In the present study of Spergularia marina (Caryophyllaceae; sand-spurrey), we examine the degree to which age-related changes in floral expression within individuals contribute to phenotypic variation in floral traits. In addition, we determine whether ontogenetic variation in floral traits can obscure two potential sources of genetic variation: (a) variation among maternal families within populations, and (b) variation among geographically proximate populations. We are also concerned with a practical issue for evolutionists who wish to measure genetic variation in floral traits among individuals or populations. Strong age-related changes in floral phenotype may result in estimates of heritability or interpopulational divergence that are sensitive to the timing of flower sampling. Under these conditions, heritability estimates, and predictions of the response to selection, will depend on the age of sampled individuals or genotypes. To examine this possibility in $S$. marina, we explored temporal variation in maternal family and population effects on offspring floral phenotype in a uniform environment.

We address three sets of questions. (1) Are there evolutionarily significant sources of phenotypic variation in floral traits in $S$. marina? Do some floral traits exhibit stronger evidence for genetic variation than others? Do week $\times$ maternal family or week $\times$ population interactions significantly affect floral trait expression, indicating the presence of genetic variation in the degree of ontogenetic change? (2) Have populations differentiated with respect to phenotypic means, the magnitude of genetic variation, or the expression of ontogenetic change in floral traits? Do floral traits appear to be evolving independently among populations, suggesting that these traits are subject to different evolutionary pressures in different populations? (3) Do flowers sampled at different times show different levels of among-family or among-population variation?

\section{Materials and methods}

\section{Study organism}

Spergularia marina (L.) Griseb. provides an unusual opportunity to detect evolutionarily significant sources of floral trait variation, as this autogamous species exhibits a remarkably high degree of phenotypic variation in both primary and secondary sexual characters (Delesalle \& Mazer, 1995). It is an annual halophytic herb with a four- to six-month life cycle and a widespread distribution in coastal saltmarshes and wetlands in Europe, North America, and South Africa (Sterk, 1969a; Cusick, 1983; Torstensson, 1987; Ungar, 1992; Redbo-Torstensson, 1994). Californian populations generally germinate in February or March and seed production occurs from May to July, depending on local weather conditions. The species is easily cultivated in the greenhouse using fresh water; seeds readily germinate following a two-week vernalization treatment in wet sand. Flowers self-pollinate while still in the bud and seed dehiscence occurs approximately two weeks later. Redbo-Torstensson (1994) has pointed out that seeds collected in the field from a maternal plant are likely to be nearly 100 per cent selfed; like us, he has never seen pollinators visit $S$. marina in the field. Plants cultivated in the greenhouse typically have 100 per cent fruit set; and Sterk and Dijkhuizen (1972) have calculated the maximum outcrossing rate in wild populations to be 1-2 per cent.

Spergularia marina flowers vary dramatically with respect to all floral traits that have been observed. In greenhouse-raised plants in California, flowers contain: 46-182 ovules (e.g. the plants grown for this study); zero (rarely) to eight normal anthers (Sterk, 1969a,b reports up to 10 anthers); zero15000 pollen grains (mean pollen production $\approx 5500$ grains per flower); zero to five 'abnormal' anthers (these range from anthers with petal-like protrusions, to petals with strips of pollen-bearing sacs); and one (rarely zero) to five petals. The area of a single petal (estimated as maximum petal length $\times$ width) varies from $0.72-10.32 \mathrm{~mm}^{2}$, and 
total corolla area (estimated as petal area $\times$ petal number) varies from $1.25-51.60 \mathrm{~mm}^{2}$ (flowers used in this study). The production of normal anthers is significantly and positively correlated with pollen production (Delesalle \& Mazer, 1995), so measures of male and female investment per flower are easily estimated.

\section{Study populations}

Seeds were collected in June 1991 from four wild populations of $S$. marina near Santa Barbara, California. Two populations are located in the Carpinteria Salt Marsh Reserve, a nature preserve within the University of California (UC) Natural Reserve System. The 'Apple Street Creek' (ASC) population is on a berm slope adjacent to an east-west flowing creek subject to tidal influxes of brackish water. The 'Santa Monica Berm' (SMB) population is located $0.6 \mathrm{~km}$ to the south-east of ASC on a drier and more elevated berm parallel to the north-south flowing Santa Monica Creek. The soil at both sites is sandy dredge spoil deposited after the dredging of these creeks in 1980. The other two populations are on UC property in Goleta, California. The 'Coal Oil Point' (COP) population inhabits the sandy bottom of the western margin of Devereux Slough. The 'Married Student Housing' (MSH) population is located on the margins of Goleta Slough, which traverses the property of a UC student housing development. Mature seeds were collected from 50 plants per population, stored separately by plant in paper envelopes, and refrigerated until January 1992.

\section{Experimental design}

We used seeds from 10 maternal plants chosen at random from each population. In the greenhouse, we sowed seeds from each maternal plant in four 4-inch plastic pots containing UC 'xeric' mix (a three-inch layer at the bottom of the pot) covered by a one-inch layer of sand and topped with a 1/4-inch layer of 1/4-inch gravel (to stabilize the tiny seedlings). About 40 seeds were placed on the surface of each pot, and emerging seedlings were thinned to provide one seedling per pot (the selected seedling was randomly chosen from among approximately 15 equally robust seedlings). As flowering began (April, 1992), a total of five flowers per plant was collected at one-week intervals. For each individual plant, the first flower was collected as soon as the plant started flowering; additional flowers were collected from each plant at one-week intervals. We collected a total of 644 flowers; some maternal families did not survive to flower or did not produce flowers for the full five weeks, preventing a perfectly balanced design. ASC, COP, MSH, and SMB contributed flowers from nine, eight, nine, and 10 maternal families, respectively, and a total of 130 adult plants produced flowers (all but six plants contributed five flowers). Flowers were placed individually in sealed microcentrifuge tubes and frozen until they were dissected under a stereomicroscope. The following data were recorded from each flower: the number of ovules, the number of normal and abnormal anthers, petal number, petal length $(\mathrm{mm})$, and petal width (mm; at the widest point). The area of one 'typical' petal (neither the largest nor the smallest was selected) was estimated as its length $\times$ width, and the total corolla area of each flower was estimated as petal number $\times$ the area of the single petal.

\section{Statistical analyses}

Analyses of variance Analyses of variance (ANOVAs) were conducted on four types of data sets: (1) all populations and weeks pooled (all flowers included); (2) each population analysed separately; (3) populations pooled but flowers from each week analysed separately; and (4) a data set including all flowers from one randomly selected plant per maternal family ( $N=180$ flowers). This last data set was used to estimate the repeatability of floral traits, a quantitative genetic parameter that expresses the correlation between measures recorded repeatedly within individuals (Falconer, 1989). Sequentially measured traits with low repeatabilities exhibit high levels of ontogenetic change; for such traits, genetic and ontogenetic sources of variation are most easily confounded when sampling maternal families or populations.

ANOVAS were conducted using SUPERANOVA and STATVIEW (Abacus, Inc.); mean squares (MS) were estimated from Type III sums of squares. $F$-tests used to detect significant effects are described in the table captions (see Results section). Floral traits (except the number of normal anthers per flower) were highly homoscedastic with respect to week (Bartlett test and Hartley test; Neter et al., 1985) and all were unimodal. For seven out of 12 homoscedasticity tests (six floral traits tested for homoscedasticity among weeks and among populations), the ratio of the highest to the lowest sample variance was less than 1.60; for the remaining five tests, this ratio was $1.60-2.00$. No transformations markedly improved normality and homoscedasticity, so untransformed values were used. $P$-values reported here were not adjusted for multiple tests. 
Interpretation of statistically significant maternal family effects on progeny phenotype It is reasonable to infer that the maternal family effects on progeny phenotype detected in this study have a genetic basis. Strong phenotypic differences in vegetative and morphological characters that we have observed among maternal families in the greenhouse and the high level of autogamy in $S$. marina suggest that maternal families represent distinct genotypes. Also, although environmental differences among maternal plants in the field can generate statistically significant maternal family effects on the floral phenotype of greenhouse-raised progeny, environmentally induced maternal effects are often most likely to be expressed in traits that appear early in the life cycle (but see Schmid \& Dolt, 1994 for some exceptions). As the floral traits examined in this study are expressed relatively late in the life cycle, this potential effect should be minimal, such that variation observed among greenhouse-raised maternal sibships should reflect genetic differences.

ANOVAS across populations Pooling all data, threefactor repeated measures ANOVAS were conducted to detect significant effects of population, maternal family (nested within population), sampling week, and their interactions on floral trait means. Two-factor nested ANOVAs (seeking population and maternal family effects [nested within populations]) were also performed to determine whether excluding week from the model would make it more difficult to detect genetic sources of variation. In the threefactor ANOVAS, significant week $\times$ population interactions indicate that the magnitude and/or the direction of temporal changes in floral phenotype differ among populations. When this obtains, the magnitude of interpopulation differences and/or the ranks of the population means depend upon the sampling week. Similarly, significant week $\times$ maternal family interactions indicate that maternal families express different types of temporal changes in floral phenotype such that the magnitude of among-family differences (or the ranks of maternal family means) depend upon the week of floral sampling. Both types of interactions indicate the presence of genetic variation in the expression ontogenetic effects.

ANOVAS within each population We performed two-factor repeated measures ANOVAS on each population separately to detect significant effects of maternal family, sampling week, and their interaction on progeny phenotype. These ANOvas also identified those traits that express the highest (and lowest) levels of maternally inherited variation and those that are the most (and least) subject to temporal changes in phenotype. We also conducted one-way ANOVAs within each population to detect significant differences among maternal family means, excluding the week effect from the model. The comparison of these one-way anOVAs to the repeated measures ANOVAS allowed us to determine whether excluding sampling week from the model influences the ability of the ANOVA to detect significant maternal family effects within populations.

ANOVAS by week ANOVAS were conducted on flowers representing each sampling week separately to determine whether the ability to detect interpopulation divergence or differences among maternal families depends on the date of flower sampling. For data representing each of the five sampling weeks, two-way nested ANOVAs were conducted to detect significant population and maternal family effects (nested within population) on floral phenotype.

\section{Results}

\section{Repeatability of floral traits}

The repeatabilities of all floral traits were very low (less than 0.20). For ovule number per flower, the repeatability was 0.1916 ; for the number of normal anthers 0.0180; for the number of abnormal anthers 0.0984 ; petal number 0.1227 ; single petal area 0.0736 ; and total petal area 0.0604 . With repeatabilities of $0.10-0.20$, the reduction (by 70 per cent) in the variance associated with the mean of five measurements compared to the variance associated with a single measurement indicates a considerable gain in precision. In $S$. marina, then, the gain in accuracy achieved by measuring five flowers justifies this replication (Falconer, 1989).

\section{Analyses of variance: ANOvAS across populations}

Population and maternal family effects Populations have diverged significantly in floral trait expression. There were significant differences among population means for all traits except the number of ovules and petals per flower (Table 1). Populations also differed in their pattern of floral investment; no population universally exceeded the others with respect to the phenotypic values of floral traits (Fig. 1). For example, flowers of ASC genotypes produced larger petals than those from other populations but produced relatively few anthers, whereas flowers of COP genotypes exhibited high normal anther production but relatively small petals. All traits

(C) The Genetical Society of Great Britain, Heredity, 77, 269--281. 
except the number of abnormal anthers per flower exhibited maternal family effects on progeny phenotype, suggesting that $S$. marina harbours significant genetic variation in these traits (Table 1).

Effects of sampling week All traits except the number of abnormal anthers per flower exhibited significant differences among sampling week means (Table 1). Traits differed greatly in their sensitivity to sampling date; $F$-values expressing the ratio of the mean squares (MS) for the week effect to the MS of its error term varied from 1.14 (for abnormal anthers) to 34.37 (for ovule number). Moreover, traits showed neither consistent reductions nor increases in phenotypic value over time; each trait responded differently to the time of floral sampling (Fig. 1).

Week $\times$ population and week $\times$ maternal family interactions The three-factor repeated measures ANOVAS detected no strong interactions to suggest that populations differed with respect to the effects of sampling week on floral phenotype, or that sampling weeks differed in the magnitude of interpopulation divergence, except in the case of the number of ovules per flower (Table 1). Similarly, except in the case of ovule number per flower, there were no week $\times$ maternal family interactions; that is,
Fig, 1 Means and standard errors (vertical bars) of floral traits for greenhouse-raised Spergularia marina sampled from four wild populations and observed at weekly intervals. Asterisks indicate sampling weeks for which ANOVAs detected significant differences among population means (Table 4). Week $\times$ population interactions are suggested when lines cross or when the magnitude of interpopulation differences changes over time, although the repeated measures ANOVA conducted across populations (Table 1) detected a significant week$x$ population interaction only for the mean number of ovules per flower. For most traits, however, weeks differed with respect to the statistical significance of interpopulation differences.
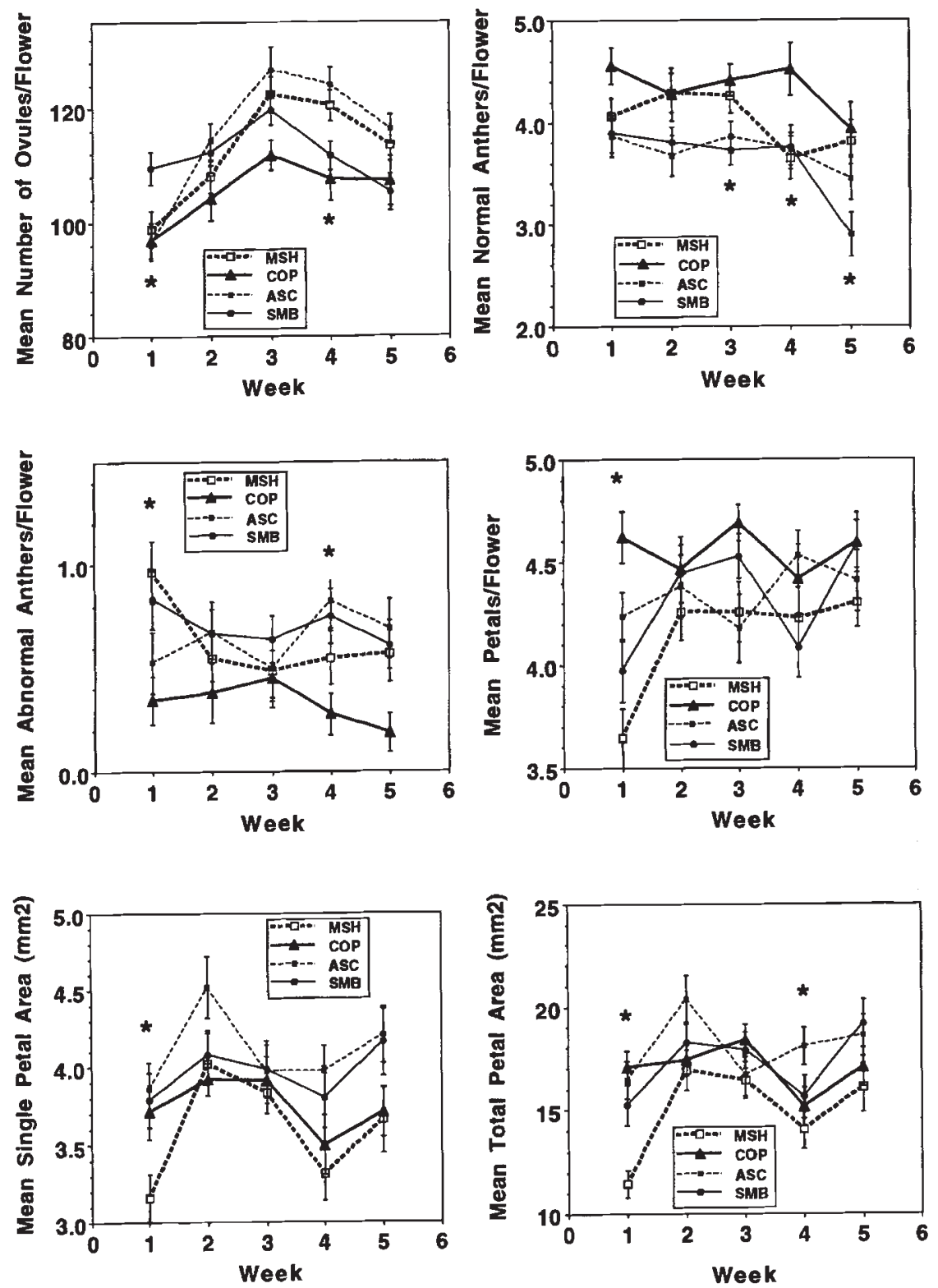
Table 1 Repeated measures ANOVAs to detect significant population, maternal family, sampling week, and interaction effects on floral traits of Spergularia marina

\begin{tabular}{|c|c|c|c|c|c|c|c|c|c|c|c|c|}
\hline \multirow[b]{2}{*}{ Source } & \multicolumn{4}{|c|}{ Ovules per flower } & \multicolumn{4}{|c|}{$\begin{array}{l}\text { Normal anthers per } \\
\text { flower }\end{array}$} & \multicolumn{4}{|c|}{$\begin{array}{c}\text { Abnormal anthers per } \\
\text { flower }\end{array}$} \\
\hline & d.f. & MS & $F$ & $P$ & d.f. & MS & $F$ & $P$ & d.f. & MS & $F$ & $P$ \\
\hline Population & 3 & 2439.94 & 2.29 & 0.0973 & 3 & 11.76 & 4.89 & 0.0066 & 3 & 3.86 & 4.24 & 0.0125 \\
\hline Maternal family (population) & 32 & 1066.30 & 2.66 & 0.0002 & 32 & 2.41 & 1.96 & 0.0074 & 32 & 0.91 & 1.14 & 0.3106 \\
\hline Sibling (maternal family) & 89 & 401.25 & & & 85 & 1.23 & & & 89 & 0.80 & & \\
\hline Week & 4 & 7046.03 & 34.37 & 0.0001 & 4 & 6.13 & 5.36 & 0.0003 & 4 & 0.59 & 1.14 & 0.3386 \\
\hline Week $\times$ population & 12 & 762.78 & 2.47 & 0.0062 & 12 & 1.08 & 0.80 & 0.6494 & 12 & 0.54 & 1.17 & 0.3145 \\
\hline $\begin{array}{l}\text { Week } \times \text { maternal family } \\
\quad(\text { population })\end{array}$ & 128 & 309.13 & 1.51 & 0.0017 & 128 & 1.35 & 1.18 & 0.1252 & 128 & 0.46 & 0.89 & 0.7811 \\
\hline \multirow[t]{2}{*}{ Week $\times$ sibling (maternal family) } & 356 & 205.04 & & & 340 & 1.15 & & & 356 & 0.52 & & \\
\hline & & Petals pe & ir flowe & & \multicolumn{4}{|c|}{$\begin{array}{l}\text { Single petal area per } \\
\text { flower }\end{array}$} & \multicolumn{4}{|c|}{$\begin{array}{l}\text { Total petal area per } \\
\text { flower }\end{array}$} \\
\hline Source & d.f. & MS & $F$ & $P$ & d.f. & MS & $F$ & $P$ & d.f. & MS & $F$ & $P$ \\
\hline Population & 3 & 3.54 & 2.34 & 0.0916 & 3 & 6.97 & 3.62 & 0.0234 & 3 & 233.85 & 3.40 & 0.0295 \\
\hline Maternal family (population) & 32 & 1.51 & 2.39 & 0.0007 & 32 & 1.92 & 2.17 & 0.0023 & 32 & 68.80 & 3.09 & 0.0001 \\
\hline Sibling (maternal family) & 88 & 0.63 & & & 89 & 0.89 & & & 88 & 22.30 & & \\
\hline Week & 4 & 1.97 & 3.40 & 0.0096 & 4 & 5.10 & 5.01 & 0.0006 & 4 & 212.70 & 7.22 & 0.0001 \\
\hline Week $\times$ population & 12 & 0.96 & 1.65 & 0.0852 & 12 & 0.94 & 0.97 & 0.4851 & 12 & 49.10 & 1.76 & 0.0618 \\
\hline $\begin{array}{l}\text { Week } \times \text { maternal family } \\
\quad(\text { population })\end{array}$ & 128 & 0.58 & 1.00 & 0.4821 & 128 & 0.98 & 0.96 & 0.6035 & 128 & 27.91 & 0.95 & 0.6365 \\
\hline Week $\times$ sibling (maternal family) & 352 & 0.58 & & & 356 & 1.02 & & & 352 & 29.47 & & \\
\hline
\end{tabular}

Significant results $(P<0.05)$ appear in boldface.

$F$-values to detect population effects use the MS for the maternal family effect in the denominator.

$F$-values to detect maternal family effects use the MS for the sibling effect in the denominator.

$F$-values for the week effect and the week $\times$ maternal family effect use the MS for the week $\times$ sibling (maternal family)

effect in the denominator.

$F$-values for the week $\times$ population effect use the MS for the week $\times$ maternal family (population) effect in the

denominator.

there were no apparent differences among maternal families with respect to the effect of week on floral phenotype nor differences among weeks with respect to the amount of variation among maternal families.

ANOVAS that exclude week as a main effect The two-factor nested ANOVAS conducted on pooled populations (population and maternal family as main effects) provided results nearly identical to the repeated measures ANOVAS (Table 2). The models differed with respect to the detection of maternal family effects on the number of abnormal anthers per flower: the two-factor nested ANOVA detected statistically significant differences among maternal families whereas the repeated measures ANOVA did not. For this trait, the failure to control statistically for the effects of sampling week (which were not significant; Table 1) improved the ability to detect maternally transmitted variation. This result reflects the fact that in the two-factor ANOVA there was a large increase in the degrees of freedom associated with the denominator of the $F$-value testing for the maternal family effect (608 d.f. [Table 2] vs. 89 d.f. [Table 1]).

\section{ANOVAS within each population}

Maternal family effects within populations Populations differed with respect to the combination of traits that exhibited significant maternal family effects (Table 3). For each trait, at least one population appeared to have been purged of genetic variation.

Sampling week effects within populations Populations differ with respect to the strength of the 
Table 2 Nested ANOVAs to detect significant differences among population and maternal family (nested within populations) means for floral traits of Spergularia marina, excluding the effect of sampling week

\begin{tabular}{|c|c|c|c|c|c|c|c|c|c|c|c|c|}
\hline \multirow[b]{2}{*}{ Source } & \multicolumn{4}{|c|}{ Ovules per flower } & \multicolumn{4}{|c|}{ Normal anthers per flower } & \multicolumn{4}{|c|}{ Abnormal anthers per flower } \\
\hline & d.f. & MS & $F$ & $P$ & d.f. & MS & $F$ & $P$ & d.f. & MS & $F$ & $P$ \\
\hline Population & 3 & 2433.09 & 2.26 & 0.1009 & 3 & 17.559 & 6.50 & 0.0015 & 3 & 3.960 & 4.37 & 0.0109 \\
\hline Maternal family ( & 32 & 1079.00 & 3.39 & 0.0001 & 32 & 2.700 & 2.24 & 0.0001 & 32 & 0.906 & 1.67 & 0.0123 \\
\hline \multirow[t]{2}{*}{ Residual } & 608 & 317.99 & & & 608 & 1.205 & & & 608 & 0.541 & & \\
\hline & \multicolumn{4}{|c|}{ Petals per flower } & \multicolumn{4}{|c|}{ Single petal area } & \multicolumn{4}{|c|}{ Total petal area } \\
\hline Source & d.f. & MS & $F$ & $P$ & d.f. & MS & $F$ & $P$ & d.f. & MS & $F$ & $P$ \\
\hline Populatio & 3 & 3.788 & 2.41 & 0.08 & 3 & 8.027 & 4.19 & 0.0131 & 3 & 264.498 & 3.70 & 0.0216 \\
\hline Maternal fa & 32 & 1.574 & 2.63 & 0.0001 & 32 & 1.918 & 1.92 & 0.0020 & 32 & 71.552 & 2.42 & 0.0001 \\
\hline Residual & 608 & 0.599 & & & 608 & 1.001 & & & 608 & 29.521 & & \\
\hline
\end{tabular}

Data from all sampled flowers were used in these analyses.

$F$-values to detect population effects use the mean square (MS) for the maternal family effect in the denominator.

Significant results $(P<0.05)$ appear in boldface.

sampling week effect on all traits except for the number of abnormal anthers per flower (which showed no significant week effect in any population; Table 3). This result suggests the presence of a week $\times$ population interaction for all traits except abnormal anthers, which contrasts with the results of the three-factor ANOVAs (Table 1).

Table 3 and Fig. 1 show that traits differ in the consistency with which they exhibit significant temporal changes in phenotype across populations. For example, ovule number per flower differed significantly among weeks in plants from all four populations, whereas all other traits (except abnormal anther production) exhibited significant week effects in only a subset of populations. Traits also differed in the pattern of temporal change. For example, whereas ovule production per flower peaked at week 3 , total petal area per flower tended to peak at week 2 .

Week $\times$ maternal family interaction The ANOVAS performed within each population detected no strong differences among maternal families in the effect of sampling week on floral traits, except in the case of ovule number per flower (note the significant interaction in ASC and SMB [Table 3]). This result is consistent with the repeated measures ANOVA across populations (Table 1).

Excluding week from the model The exclusion of week effects from the population-specific ANOVAS led to qualitatively different results in six out of 24 tests for significant maternal family effects (results not shown). There was no tendency for the exclusion of week from the model either to enhance or to reduce the likelihood of detecting maternal family effects. In three cases, excluding week from the model resulted in the detection of significant maternal family effects where the more complete model failed to do so; in three cases, the converse was true.

\section{ANOVAS by week}

The ability to detect statistically significant differences among populations and among maternal families within populations depended on the week at which flowers were sampled. The expression of significant differences among population means depended strongly on the week at which flowers were sampled (Table 4; Fig. 1). Flowers sampled at week 1 show the strongest evidence for interpopulation divergence in these traits. Similarly, the expression of variation among maternal families within populations depended on sampling week. This result suggests the presence of a week $\times$ maternal family interaction even though this was detected in the complete ANOVA only for ovule number per flower (Table 1).

\section{Discussion}

The results of the present study shed light on three issues. First, when sampling modular traits with low repeatabilities, the ability to detect genetic variation within or among populations may depend strongly on the time at which the traits are sampled. In the 


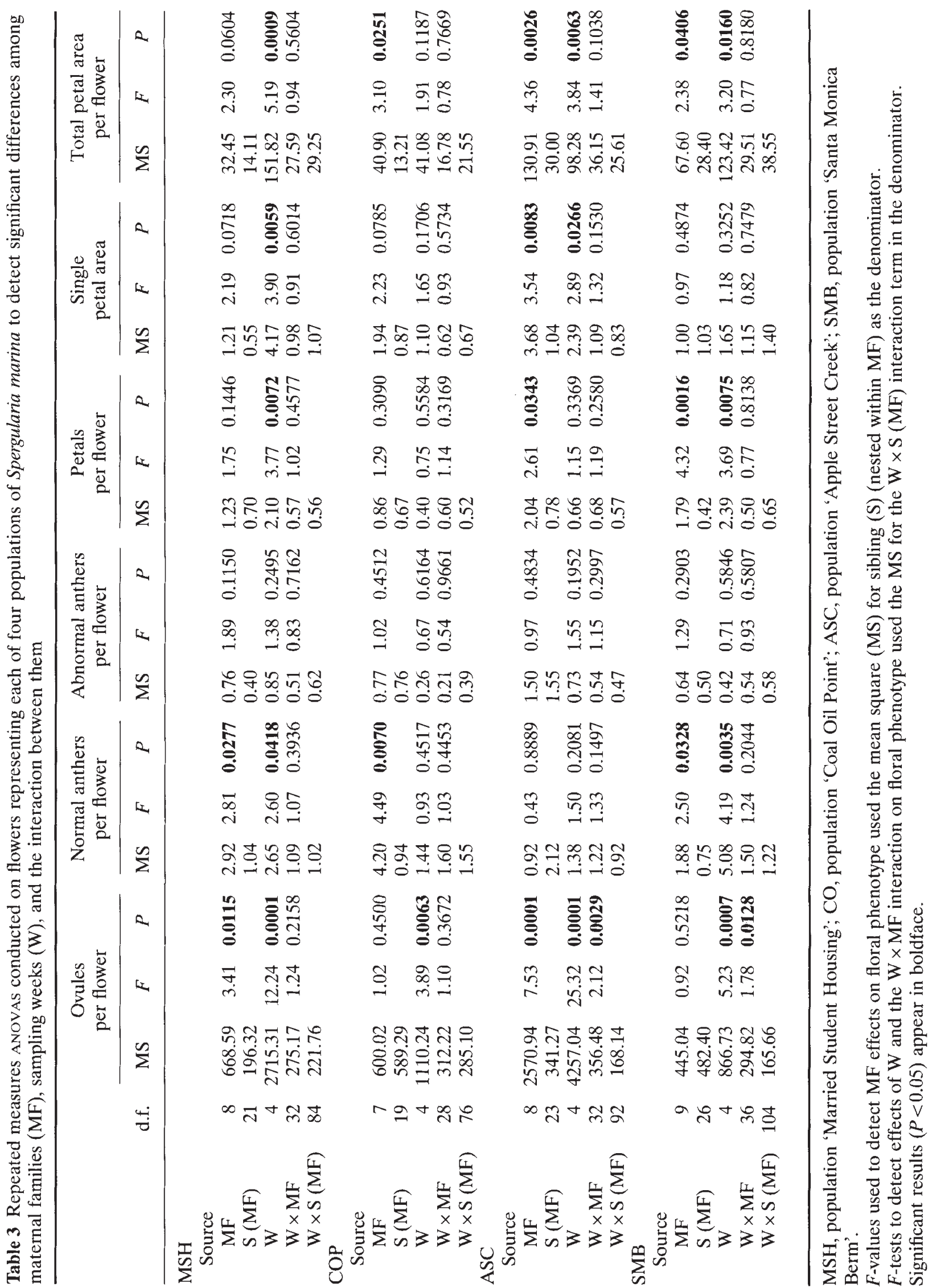


case of $S$. marina, we observed significant maternal family effects on trait means for flowers sampled in some weeks but not in others. This implies that broad-sense heritability estimates used to predict the response to selection on these traits would also be sensitive to flower sampling date. Secondly, the ANOVAS offer inconsistent evidence for the presence of significant week $\times$ maternal family and week $\times$ po-

Table 4 Nested ANOvas conducted on data from each sampling week to detect significant differences among population means and among maternal family means (nested within populations) with respect to floral traits of Spergularia marina

\begin{tabular}{|c|c|c|c|c|c|c|c|c|c|c|}
\hline \multirow{2}{*}{$\begin{array}{l}\text { Week } 1 \\
\text { Source }\end{array}$} & \multirow[b]{2}{*}{ d.f. } & \multicolumn{3}{|c|}{$\begin{array}{l}\text { Ovules } \\
\text { per flower }\end{array}$} & \multicolumn{3}{|c|}{$\begin{array}{l}\text { Normal anthers } \\
\text { per flower }\end{array}$} & \multicolumn{3}{|c|}{$\begin{array}{l}\text { Abnormal anthers } \\
\text { per flower }\end{array}$} \\
\hline & & MS & $F$ & $P$ & MS & $F$ & $P$ & MS & $F$ & $P$ \\
\hline Population & 3 & 1330.26 & 3.07 & 0.0418 & 3.80 & 2.43 & 0.0836 & 2.51 & 5.54 & 0.0035 \\
\hline $\mathrm{MF}(\mathrm{P})$ & 32 & 433.61 & 1.68 & 0.0285 & 1.56 & 1.65 & 0.0325 & 0.45 & 0.64 & 0.9235 \\
\hline \multirow[t]{2}{*}{ Error } & 94 & 258.04 & & & 0.95 & & & 0.71 & & \\
\hline & & \multicolumn{3}{|c|}{$\begin{array}{l}\text { Petals } \\
\text { per flower }\end{array}$} & \multicolumn{3}{|c|}{$\begin{array}{l}\text { Single petal } \\
\text { area }\end{array}$} & \multicolumn{3}{|c|}{$\begin{array}{c}\text { Total petal area } \\
\text { per flower }\end{array}$} \\
\hline Source & d.f. & MS & $F$ & $P$ & MS & $F$ & $P$ & MS & $F$ & $P$ \\
\hline Population & 3 & 4.51 & 5.73 & 0.0029 & 3.05 & 3.57 & 0.0246 & 181.50 & 5.84 & 0.0027 \\
\hline $\mathrm{MF}(\mathrm{P})$ & 32 & 0.79 & 1.43 & 0.0960 & 0.85 & 0.89 & 0.6305 & 31.09 & 1.45 & 0.0873 \\
\hline Error & 94 & 0.55 & & & 0.95 & & & 21.47 & & \\
\hline \multicolumn{2}{|l|}{ Week 2} & \multicolumn{3}{|c|}{$\begin{array}{l}\text { Ovules } \\
\text { per flower }\end{array}$} & \multicolumn{3}{|c|}{$\begin{array}{l}\text { Normal anthers } \\
\text { per flower }\end{array}$} & \multicolumn{3}{|c|}{$\begin{array}{c}\text { Abnormal anthers } \\
\text { per flower }\end{array}$} \\
\hline Source & d.f. & MS & $F$ & $P$ & MS & $F$ & $P$ & MS & $F$ & $P$ \\
\hline Population & 3 & 527.39 & 1.37 & 0.2688 & 3.35 & 1.77 & 0.1730 & 0.55 & 0.87 & 0.4670 \\
\hline $\mathrm{MF}(\mathrm{P})$ & 32 & 384.17 & 1.48 & 0.0770 & 1.90 & 1.73 & 0.0228 & 0.63 & 1.18 & 0.2686 \\
\hline \multirow[t]{2}{*}{ Error } & 93 & 260.20 & & & 1.10 & & & 0.53 & & \\
\hline & & \multicolumn{3}{|c|}{$\begin{array}{c}\text { Petals } \\
\text { per flower }\end{array}$} & \multicolumn{3}{|c|}{$\begin{array}{l}\text { Single petal } \\
\text { area }\end{array}$} & \multicolumn{3}{|c|}{$\begin{array}{l}\text { Total petal area } \\
\text { per flower }\end{array}$} \\
\hline Source & d.f. & MS & $F$ & $P$ & MS & $F$ & $P$ & MS & $F$ & $P$ \\
\hline Population & 3 & 0.24 & 0.32 & 0.8135 & 2.47 & 2.45 & 0.0818 & 82.80 & 2.26 & 0.0999 \\
\hline $\mathrm{MF}(\mathrm{P})$ & 32 & 0.77 & 1.14 & 0.3083 & 1.01 & 1.05 & 0.4126 & 36.57 & 1.22 & 0.2316 \\
\hline Error & 93 & 0.68 & & & 0.96 & & & 30.04 & & \\
\hline \multicolumn{2}{|l|}{ Week 3} & \multicolumn{3}{|c|}{$\begin{array}{l}\text { Ovules } \\
\text { per flower }\end{array}$} & \multicolumn{3}{|c|}{$\begin{array}{l}\text { Normal anthers } \\
\text { per flower }\end{array}$} & \multicolumn{3}{|c|}{$\begin{array}{l}\text { Abnormal anthers } \\
\text { per flower }\end{array}$} \\
\hline Source & d.f. & MS & $F$ & $P$ & MS & $F$ & $P$ & MS & $F$ & $P$ \\
\hline Population & 3 & 1130.88 & 2.00 & 0.1344 & 3.65 & 3.64 & 0.0231 & 0.13 & 0.24 & 0.8685 \\
\hline $\mathrm{MF}(\mathrm{P})$ & 32 & 566.60 & 2.33 & 0.0009 & 1.00 & 1.38 & 0.1179 & 0.54 & 0.91 & 0.6129 \\
\hline \multirow[t]{2}{*}{ Error } & 94 & 242.77 & & & \multirow{2}{*}{\multicolumn{3}{|c|}{$\begin{array}{l}\text { Single petal } \\
\text { area }\end{array}$}} & 0.60 & & \\
\hline & & \multicolumn{3}{|c|}{$\begin{array}{l}\text { Petals } \\
\text { per flower }\end{array}$} & & & & \multicolumn{3}{|c|}{$\begin{array}{l}\text { Total petal area } \\
\text { per flower }\end{array}$} \\
\hline Source & d.f. & MS & $F$ & $P$ & MS & $F$ & $P$ & MS & $F$ & $P$ \\
\hline Populatio & 3 & 1.62 & 1.97 & 0.1382 & 0.10 & 0.13 & 0.9398 & 21.51 & 0.70 & 0.5586 \\
\hline $\mathrm{MF}(\mathrm{P})$ & 32 & 0.82 & 1.68 & 0.0285 & 0.72 & 0.79 & 0.7737 & 30.70 & 1.23 & 0.2216 \\
\hline Error & 94 & 0.49 & & & 0.92 & & & 24.99 & & \\
\hline
\end{tabular}


Table 4 Continued

\begin{tabular}{|c|c|c|c|c|c|c|c|c|c|c|}
\hline \multirow{2}{*}{$\begin{array}{l}\text { Week } 4 \\
\text { Source }\end{array}$} & \multirow[b]{2}{*}{ d.f. } & \multicolumn{3}{|c|}{$\begin{array}{l}\text { Ovules } \\
\text { per flower }\end{array}$} & \multicolumn{3}{|c|}{$\begin{array}{l}\text { Normal anthers } \\
\text { per flower }\end{array}$} & \multicolumn{3}{|c|}{$\begin{array}{l}\text { Abnormal anthers } \\
\text { per flower }\end{array}$} \\
\hline & & MS & $F$ & $P$ & MS & $F$ & $P$ & MS & $F$ & $P$ \\
\hline Population & 3 & 1701.66 & 3.49 & 0.0269 & 5.05 & 2.90 & 0.0499 & 1.88 & 3.76 & 0.0203 \\
\hline $\mathrm{MF}(\mathrm{P})$ & 32 & 488.23 & 2.26 & 0.0013 & 1.74 & 1.32 & 0.1533 & 0.50 & 0.96 & 0.5430 \\
\hline \multirow[t]{2}{*}{ Error } & 94 & 215.71 & & & 1.32 & & & 0.52 & & \\
\hline & & \multicolumn{3}{|c|}{$\begin{array}{c}\text { Petals } \\
\text { per flower }\end{array}$} & \multicolumn{3}{|c|}{$\begin{array}{l}\text { Single petal } \\
\text { area }\end{array}$} & \multicolumn{3}{|c|}{$\begin{array}{l}\text { Total petal area } \\
\text { per flower }\end{array}$} \\
\hline Source & d.f. & MS & $F$ & $P$ & MS & $F$ & $P$ & MS & $F$ & $P$ \\
\hline Population & 3 & 1.30 & 1.58 & 0.2137 & 2.88 & 2.39 & 0.0873 & 103.37 & 4.26 & 0.0122 \\
\hline $\mathrm{MF}(\mathrm{P})$ & 32 & 0.82 & 1.26 & 0.1989 & 1.21 & 1.13 & 0.3151 & 24.25 & 0.76 & 0.8117 \\
\hline Error & 94 & 0.65 & & & 1.07 & & & 32.00 & & \\
\hline \multicolumn{2}{|l|}{ Week 5} & \multicolumn{3}{|c|}{$\begin{array}{l}\text { Ovules } \\
\text { per flower }\end{array}$} & \multicolumn{3}{|c|}{$\begin{array}{l}\text { Normal anthers } \\
\text { per flower }\end{array}$} & \multicolumn{3}{|c|}{$\begin{array}{l}\text { Abnormal anthers } \\
\text { per flower }\end{array}$} \\
\hline Source & d.f. & MS & $F$ & $P$ & MS & $F$ & $P$ & MS & $F$ & $P$ \\
\hline Population & 3 & 876.24 & 1.87 & 0.1549 & 6.40 & 3.93 & 0.0170 & 1.43 & 2.23 & 0.1043 \\
\hline $\mathrm{MF}(\mathrm{P})$ & 32 & 469.18 & 1.80 & 0.0161 & 1.63 & 1.04 & 0.4354 & 0.64 & 1.49 & 0.0738 \\
\hline \multirow[t]{2}{*}{ Error } & 89 & 260.28 & & & 1.57 & & & 0.43 & & \\
\hline & & \multicolumn{3}{|c|}{$\begin{array}{l}\text { Petals } \\
\text { per flower }\end{array}$} & \multicolumn{3}{|c|}{$\begin{array}{l}\text { Single petal } \\
\text { area }\end{array}$} & \multicolumn{3}{|c|}{$\begin{array}{c}\text { Total petal area } \\
\text { per flower }\end{array}$} \\
\hline Source & d.f. & MS & $F$ & $P$ & MS & $F$ & $P$ & MS & $F$ & $P$ \\
\hline Population & 3 & 0.54 & 0.73 & 0.5407 & 2.60 & 1.41 & 0.2584 & 66.95 & 1.16 & 0.3394 \\
\hline $\mathrm{MF}(\mathrm{P})$ & 32 & 0.73 & 1.56 & 0.0535 & 1.85 & 1.79 & 0.0170 & 57.61 & 1.86 & 0.0117 \\
\hline Error & 89 & 0.47 & & & 1.03 & & & 30.90 & & \\
\hline
\end{tabular}

MF (P), maternal family (population).

Mean square (MS) values are based on Type III sum of squares.

$F$-values to detect population effects use the MS for the maternal family effect in the denominator.

Significant results $(P<0.05)$ appear in boldface.

pulation interactions. ANOVAS conducted on the pooled data (all populations and weeks included) found these interactions to be significant only for the number of ovules per flower, suggesting the presence of genetic variation within and among populations in the degree to which ovule number (and only this trait) changes over time (Table 1). Analysing data by population, however, suggested that the magnitude of ontogenetic variation in most floral traits varies among populations (Table 3). For example, week effects were common in $\mathrm{MSH}$ but rare in COP. Similarly, separating data by week provided evidence that for most traits the magnitude and statistical significance of among-population and among-family differences changed markedly over time (Table 4; Fig. 1). Thirdly, the phenotypic differences among populations and the populationspecific effects of sampling week on floral trait expression suggest that these populations have followed different evolutionary trajectories and that floral traits have evolved independently of one another. The latter conclusion is also supported by the observation that traits differ in the degree of their interpopulation divergence. This type of evolutionary divergence among populations with respect to the means of floral traits has also been observed by Carr \& Fenster (1994) in Mimulus guttatus and M. micranthus (Scrophulariaceae). 
Implications of the absence of week $\times$ population and week $\times$ maternal family interactions

One possible conclusion from the three-factor ANOVAS (Table 1 ) is that the week $\times$ population and week $\times$ maternal family interactions are unimportant for most traits. This would imply that there is no significant genetic variation in the nature of temporal change in floral trait expression or in the degree of phenotypic canalization of floral traits over time. In spite of nonsignificant week $\times$ population interaction terms, however, the populationspecific anOvas (Table 3 ) show that the magnitude of temporal changes in floral traits differs among populations (probably reflecting genetic differences among them). The absence of these interactions could similarly be interpreted to mean that the between-family and between-population components of variation remain constant as plants age. However, the week-specific anOvas (Table 4) show that the magnitude and significance of differences among populations and maternal families are in fact quite sensitive to the week in which flowers are sampled. Consequently, even though these interactions are not significant in the three-factor ANOVA, age-related changes in floral phenotype clearly influence the ability to detect genetic differentiation within and among populations.

\section{Do ontogenetic changes in floral traits mask genetic variation among families or populations?}

If week-to-week changes in floral traits are strong enough to mask underlying genetic variation, then ANOVAS that exclude week effects should not detect significant differences among maternal families or populations as easily as the ANOVAS that control for them. In this study, the nested two-factor ANOVAS conducted to detect population and maternal family effects on floral traits - excluding week effects from the model - did not meet this expectation. These ANOVAS detected differences among population means for the same traits as did the ANOVAs that included week effects (Table 2). In addition, these ANOVAs detected significant maternal family effects for all traits, whereas the three-factor ANOVA failed to do so for the number of abnormal anthers per flower. In sum, when all populations were pooled, the statistical control of sampling week did not improve the ability to detect significant differences among populations or maternal families.

Within populations, one-way ANOVAs that excluded week effects (maternal family as the main effect; results not shown) detected significant differ- ences among maternal families as frequently as the two-factor models. In these one-way ANOVAs, the statistical control of sampling week improved the ability to detect maternal family effects on some floral traits, but had the opposite effect on others. So, although these ANOVAS suggest that temporal variation in floral phenotype did not badly mask variation among maternal families and populations in $S$. marina, the ability of ANOVAs to detect significant genetic variation was strongly sensitive to sampling week (Table 4).

A few other studies have also detected temporal changes in the expression of genetic variation. Young \& Stanton (1990) report temporal changes in male and female investment per flower over a fiveweek period in four individuals of Raphanus sativus (Brassicaceae: wild radish). Although, across plants, pollen production and the pollen:ovule ratio declined significantly over time, they did not decline significantly in all plants, thereby creating temporal changes in the magnitude of interplant differences. In a detailed study of floral trait variation caused by genotype, inflorescence age, and population, Armbruster (1991) examined 61 genets of the tropical vine, Dalechampia scandens (Euphorbiaceae). $\mathrm{He}$ observed that several traits (gland area, glandstigma distance, and bract length) exhibited significant changes with inflorescence age and significant differences among genotypes and populations. Controlling statistically for blossom age allowed a more precise estimate of the proportions of variance attributable to genet and population. The repeated sampling of flowers in his study also revealed parallel temporal changes in several characters within inflorescences, suggesting that some traits are genetically linked. Finally, Diggle (1993) documented the effects of fruit set (a proxy for the current resource status of a plant), pollination history (hand-pollinated vs. unpollinated) and genotype on the proportion of staminate flowers per inflorescence in Solanum hirtum (Solanaceae). She detected significant differences among genotypes and pollination treatments, indicating that the reproductive history and resource status of plants could strongly influence their sex expression, potentially influencing estimates of variation among genotypes.

\section{Is there genetic variation in the degree of ontogenetic change expressed by floral traits?}

In $S$. marina, we sought genetic variation in the response to ageing (i.e. the degree of canalization of floral traits over time) at two levels: among maternal families and among populations. We found little 
evidence that maternal families differ in the magnitude of ontogenetic change of floral traits. Maternal families within populations showed similar patterns of floral change over time (except for ovule number per flower). Populations, however, differed in the extent of temporal change in floral phenotype for most traits. Evidently, populations have diverged genetically with respect to their tendency to express ontogenetic changes in particular floral traits. Until estimates are available of the effect of different kinds of temporal changes in floral expression on individual fitness, however, the evolutionary significance of this variation will remain obscure.

\section{Acknowledgements}

We have benefitted greatly from discussions with T.-L. Ashman, I. Dajoz, J. Damuth, P.-H. Gouyon, G. LeBuhn, and J. Schmitt. P. Neal, G. LeBuhn, D. Meade, S. Travers, and two anonymous reviewers offered many helpful criticisms on a previous version of the manuscript. D. Garvey and J. Bleck provided meticulous greenhouse care. This work was supported by NSF DEB-9106647 (to SJM), NSF DEB-9111249 (to VAD), and NSF DEB-9157270 to SJM. SJM is very grateful to the Centre National de Recherche Scientifique for sabbatical support at the Laboratoire d'Ecologie et Systematique des Végétaux (CNRS URA 1492) at the Université de ParisSud XI.

\section{References}

ARMBRUSTER, w. s. 1991. Multilevel analysis of morphometric data from natural plant populations: insights into ontogenetic, genetic, and selective correlations in Dalechampia scandens. Evolution, 45, 1229-1244.

ASHMAN, T. L., AND BAKER, I. 1992. Variation in floral sex allocation with time of season and currency. Ecology, 73, 1237-1243.

BRAAK, J. P., AND KHO, Y. O. 1958. Some observations on the floral biology of the carrot (Daucus carota). Euphytica, 7, 131-139.

BRADSHAW, A. D. 1965. Evolutionary significance of phenotypic plasticity in plants. Adv. Genet., 13, 115-155.

CARR, D. W. AND FENSTER, C. B. 1994. Levels of genetic variation and covariation for Mimulus (Scrophulariaceae) floral traits. Heredity, 72, 606-618.

Charnov, E. L. 1982. The Theory of Sex Allocation. Princeton University Press, Princeton, NJ.

Cusick, A. w. 1983. Spergularia (Caryophyllaceae) in Ohio. The Michigan Botanist, 22, 69--71.

DELESAlLE, v. A., AND MAZER, s. J. 1995. The structure of phenotypic variation in gender and floral traits within and among populations of Spergularia marina (Caryophyllaceae). Am. J. Bot., 82, 798-810.
DIGGLE, Р. К. 1993. Developmental plasticity, genetic variation, and the evolution of andromonoecy in Solanum hirtum (Solanaceae). Am. J. Bot., 80, 967-973.

EMMS, s. K. 1993. Andromonoecy in Zigadenus paniculatus (Liliaceae): spatial and temporal patterns of sex allocation. Am. J. Bot., 80, 914-923.

FALCONER, D. s. 1989. Introduction to Quantitative Genetics, 3rd edn. Longman Scientific and Technical, New York.

HOLTSFORD, T. P. 1985. Nonfruiting hermaphroditic flowers of Calochortus leichtlinii (Liliaceae): potential reproductive functions. Am. J. Bot., 72, 1687-1694.

KANG, H. AND PRIMACK, R. B. 1991. Temporal variation of flower and fruit size in relation to seed yield in Celandine Poppy (Chelidonium majus, Papaveraceae). Am. J. Bot., 78, 711-722.

MAZER, S. J. AND SCHICK, C. T. 1991a. Constancy of population and genetic parameters for life history and floral traits in Raphanus sativus L. I. Norms of reaction and the nature of genotype by environment interactions. Heredity, 67, 143-156.

MAZER, S. J. AND SCHICK, C. T. 1991b. Constancy of population and genetic parameters for life-history and floral traits in Raphanus sativus L. II. Effects of planting density on phenotype and heritability estimates. Evolution, 45, 1888-1907.

NETER, J., WASERMAN, W. R. AND KUTNER, M. H. 1985. Applied Linear Statistical Models, 2nd edn. Richard D. Irwin, Inc., Homewood, IL.

Nүвом, н. 1989. Temporal and spatial patterns in the production of pollen, ovules and seeds in pseudogamous blackberries (Rubus Subgenus Rubus). Holarctic Ecol, , 12, 120-129.

PELLMYR, O. 1987. Temporal patterns of ovule allocation, fruit set, and seed predation in Anemopsis macrophylla (Ranunculaceae). Bot. Mag. Tokyo, 100, 175-183.

REDBO-TORSTENSSON, P. 1994. Variation in plastic response to a salinity gradient within a population of the halophytic plant Spergularia marina. Oikos, 70, 349-358.

SCHMID, B. AND DOLT, C. 1994. Effects of maternal and paternal environment and genotype on offspring phenotype in Solidago altissima L. Evolution, 48, 1525-1549.

SCHOEN, D. 1982. Male reproductive effort and breeding system in an hermaphroditic plant. Oecologia, 53, $255-257$.

SOLOMON, B. P. 1985. Environmentally influenced changes in sex expression in an andromonoecious plant. Ecology, 66, 1321-1332.

STERK, A. A. 1969a. Biosystematic studies of Spergularia media and $S$. marina in the Netherlands I. The morphological variability of $S$. media. Acta Bot. Neerl., 18, 325-338.

STERK, A. A. $1969 \mathrm{~b}$. Reduction of the androecium in Spergularia marina (Caryophyllaceae). Acta Bot. Neerl., 19, 488-494.

STERK, A. A. AND DIJKHUIZEN, L. 1972. The relation between the genetic determination and the ecological significance of the seed wing in Spergularia media and

(c) The Genetical Society of Great Britain, Heredity, 77, 269-281. 
S. marina. Acta Bot. Neerl., 21, 481-490.

THOMPSON, J. N. 1987. The ontogeny of flowering and sex expression in divergent populations of Lomatium grayi. Oecologia, 72, 605-611.

THOMPSON, J. N. AND PELLMYR, O. 1989. Origins of variance in seed number and mass: interaction of sex expression and herbivory in Lomatium salmoniflorum. Oecologia, 79, 395-402.

тhomson, J. D. 1985. Pollination and seed set in Diervilla lonicera (Caprifoliaceae): temporal patterns of flower and ovule development. Am. J. Bot., 72, 737-740.

THOMson, J. D. 1989. Deployment of ovules and pollen among flowers within inflorescences. Evol. Trends Plants, 3, 65-68.

THOMSON, J. D. AND BARRETT, s. C. H. 1981. Temporal variation of gender in Aralia hispida Vent. (Araliaceae). Evolution, 35, 1094-1107.
THOMSON, J. D., McKENNA, M. A., AND CRUZAN, M. B. 1989. Temporal patterns of nectar and pollen production in Aralia hispida: implications for reproductve success. Ecology, 70, 1061-1068.

TORSTENSSON, P. 1987. The demography of the annual halophyte Spergularia marina on a baltic seashore meadow. Vegetatio, 68, 157-168.

UNGAR, I. A. 1992. The effect of intraspecific competition on growth, reproduction, and survival of the halophyte Spergularia marina. Int. J. Plant Sci., 153, 421-424.

YOUNG, H. J. AND STANTON, M. L. 1990. Temporal patterns of gamete production within individuals of Raphanus sativus (Brassicaceae). Can. J. Bot., 68, 480-486.

ZIMMERMAN, J. K. 1991. Ecological correlates of labile sex expression in the orchid Catasetum viridiflavum. Ecology, 72, 592-608. 